\title{
Ontogenetic development of electric-organ discharges in a mormyrid fish, the bulldog Marcusenius macrolepidotus (South African form)
}

\author{
M. Werneyer And B. Kramer* \\ Zoologisches Institut der Universität Regensburg, 93040 Regensburg, Germany
}

(Received 5 July 2005, Accepted 18 May 2006)

\begin{abstract}
The emergence and development of the electric-organ discharge (EOD) in larvae and juvenile bulldog Marcusenius macrolepidotus was investigated. Larvae hatched 4-5 days after spawning, and the first EODs were recorded on days 9 and 10 at a standard length $\left(L_{\mathrm{S}}\right)$ of $c .6 .5 \mathrm{~mm}$. The larval EOD waveform was virtually monopolar, with a strong head-positive phase followed by a weak head-negative phase of long duration. A small separate potential preceded the EOD by c. $1.6 \mathrm{~ms}$ (believed to represent postsynaptic potential from electrocyte stalks). In contrast to previous reports on Pollimyrus adspersus with its distinct larval and adult EODs, in M. macrolepidotus there was a gradual transformation of the larval into the adult EOD waveform. The transformation started at an $L_{\mathrm{S}}$ of $c .17 \mathrm{~mm}$ (at an age of $c$. 40 days), first indications being a decrease in duration of the head-negative phase, and an increase of its peak amplitude relative to that of the head-positive phase. Still later, the weak postpotential of the adult EOD emerged on the rising edge of the head-negative phase. The transformation was nearly completed at an $L_{\mathrm{S}}$ of c. $30 \mathrm{~mm}$ (at an age of $c .60$ days). Evolutionary and behavioural consequences of this alternative path of EOD ontogeny are discussed.

(C) 2006 The Authors

Journal compilation $(2006$ The Fisheries Society of the British Isles
\end{abstract}

Key words: development; electric-organ discharge; fish larvae; Mormyridae; ontogeny; reproduction.

\section{INTRODUCTION}

Electric fishes from the family Mormyridae are endowed with an electric organ that is located in their caudal peduncle and originates from muscle tissue. The electric-organ discharges (EODs) are short (in many species $<1 \mathrm{~ms}$ ) and separated by much longer and highly variable interdischarge intervals (IDIs) (Kramer, 1990, 1996; Moller, 1995; Hopkins, 1999). The EOD of an individual is highly stereotyped (Kramer \& Westby, 1985) (although some variability in the long-term may exist) and EOD waveforms are species-specific for a community (Kramer, 1996; Hopkins, 1999). In addition, mormyrids are electroreceptive and perceive their own EODs as well as those from other electric fishes. The ability to detect distortions of their self-generated electric field enables

\footnotetext{
*Author to whom correspondence should be addressed. Tel.: +49 941943 2263; fax: +49 941943 2905; email: bernd.kramer@biologie.uni-regensburg.de
} 
mormyrids to detect objects at close range (active electrolocation; Lissmann, 1958; Lissmann \& Machin, 1958) during their nocturnal activities or in muddy waters. Furthermore, signalling by EODs enables mormyrids to communicate with conspecifics (Bell et al., 1974; Bratton \& Kramer, 1989; Scheffel \& Kramer, 1997; Werneyer \& Kramer, 2002, 2005) as well as with other mormyrid species (Kramer \& Bauer, 1976; Scheffel \& Kramer, 2000, 2006) on a 'private channel', not overheard by most other fishes.

Mormyrids are difficult to breed in captivity. Although they represent the largest family of bony fishes endemic to African fresh waters (c. 200 species), their reproduction and ontogenetic development has been studied in a few species only (Kirschbaum, 1995; Kirschbaum \& Schugardt, 2002). Szabo (1960) and Heymer \& Harder (1975) demonstrated EODs in mormyrid larvae caught in the wild. The ontogenetic development of the overt motor behaviour and electric signalling in Pollimyrus adspersus (Günther) larvae was studied by Kramer \& Postner (1997).

The ontogenetic development of the electric organ and its EOD was studied in detail only in P. adspersus even though Pollimyrus isidori (Valenciennes) may be mentioned as the studied species. After comparing specimens from different laboratories, Crawford (1997) concluded that previous studies on the mormyrid $P$. isidori have apparently all used the sibling species $P$. adspersus rather than $P$. isidori. Therefore, unless the distinction between the two species is specifically addressed in a study, it is assumed here, that $P$. adspersus was used.

Pollimyrus adspersus larvae develop a larval electric organ in the body trunk (Denizot et al., 1978), generating a distinct larval EOD (Westby \& Kirschbaum, 1977). The larval electric organ degenerates later on, and is functionally replaced by the adult electric organ in the caudal peduncle (Denizot et al., 1982), generating a distinct adult EOD. During a short transitional period both electric organs are active, an adult EOD follows each larval EOD by a delay of c. $0.7 \mathrm{~ms}$ (Denizot et al., 1978; Westby \& Kirschbaum, 1978). The same path of EOD ontogeny was observed in offspring of confirmed P. adspersus (Postner \& Kramer, 1995; Kramer, 1996; Kramer \& Postner, 1997).

The present study investigated the development of the EOD in larvae of Marcusenius macrolepidotus (Peters) (South African form), which differs considerably from the development of the EOD in P. adspersus.

\section{MATERIALS AND METHODS}

The parent fish originated from a group of $M$. macrolepidotus that were caught in 1997 in the Crocodile River, Mpumalanga Province, South Africa, and immediately exported to Germany where they were kept in aquaria (Werneyer \& Kramer, 2002). Prior to spawning, the male and the female were kept in an aquarium of their own $(240 \times$ $50 \times 60 \mathrm{~cm}$ high), separating the female from the male with a mesh partition. Fish spawned after removal of the mesh partition (water temperature, $22 \cdot 1^{\circ} \mathrm{C}$; conductivity $102 \mu \mathrm{S} \mathrm{cm}-1)$. Larva age and the numbering of days refer to the day of spawning as day 0 (Werneyer \& Kramer, 2005).

About 300-500 eggs were released within c. 20 min, most of them scattered all about the glass floor of the aquarium. When spawning activity waned, the parent fish were removed from the aquarium but the eggs were left in place. Several times daily any dead eggs were removed (they turned white and would finally burst). Using a pipette 
some of the eggs were carefully transferred into small plastic rearing tanks of $1 \cdot 2-1 \cdot 71$ that floated in the aquarium where they were continuously supplied with a weak water current by air-driven filters. Dead eggs were regularly replaced with eggs from the aquarium. Two days after spawning, two rearing tanks were transferred into another aquarium $(70 \times 45 \times 45 \mathrm{~cm}$ high $)$ with an external filter and an external ultraviolet light for sterilization of the water. After hatching, the larvae were left in the rearing tanks, which offered small plastic tubes (diameter, $1-1.5 \mathrm{~cm}$; length, $5 \mathrm{~cm}$ ) and Java moss (Vesicularia dubyana) for shelter. Later on, the larvae were released into the aquarium where many hiding places were present (water plants, stones, driftwood, pieces of flower pots or perforated bricks). Larvae and juvenile fish were transferred into larger aquaria several times within the next months. Water temperature was maintained at $24^{\circ} \mathrm{C}$, water conductivity was $89-142 \mu \mathrm{S} \mathrm{cm}^{-1}$.

Feeding of the larvae began on day 9 , when they received planktonic organisms from a pond and Artemia sp. naupliae. From day 37 on, chopped Chironomus sp. larvae and frozen Cyclops sp. were added. Within the next 4 weeks, frozen or live Chironomus sp. larvae were introduced.

Up to two-thirds of the aquarium water was exchanged by fresh water of 90-120 $\mu \mathrm{S} \mathrm{cm}^{-1}$ per week. Thus, strong changes in conductivity, which could have evoked changes in EOD waveform, were avoided (Kramer \& Kuhn, 1993). In addition, after a major water exchange, no EOD waveforms were recorded for several days. Up to day 17 larval EODs were recorded in small, oval-shaped glass cuvettes of 1.0 or $3.5 \mathrm{ml}$ capacity, depending on larva size, fitted with platinum electrodes at opposite ends. As larvae grew, cylindrical glass dishes of increasing size were used (from $62 \mathrm{~mm}$ diameter and $31.5 \mathrm{~mm}$ high to $115 \mathrm{~mm}$ diameter and $65 \mathrm{~mm}$ high), fitted with carbon electrodes (carbon rods, isolated except for their tips of $c$. $2 \mathrm{~mm}$ in diameter and 4-5 $\mathrm{mm}$ length; distance of electrodes increased with size of glass dishes). From day 34 on, the glass dishes were placed on a mount at the surface of a temperature-controlled aquarium $\left(24^{\circ} \mathrm{C}\right.$, measured with an electronic meter, LF 91, WTW Wissenschaftlich-Technische Werkstätten, Weilheim, Germany). From day 41 on, water temperature in the aquarium and the glass dishes was measured using a digital thermometer (Keithley 817A, Ni/ $\mathrm{CrNi}$ element; $0 \cdot 1^{\circ} \mathrm{C}$ resolution). From day 119 on, EODs were recorded within a rearing tank floating in the aquarium where the juvenile fish were kept. The last EOD recording was performed at an age of 406 days; the fish were caught within their aquarium in a small fishnet, where they usually remained motionless.

Recordings were made using differential amplifiers with fixed gain $(\times 10$ or $\times 100)$ or adjustable gain (from $c . \times 2$ to $\times 100$ ), bandwidth $1 \mathrm{~Hz}-100 \mathrm{kHz}$ (Elektronikwerkstätten, Universität Regensburg) and a digital oscilloscope (TDS 420, Tektronix Holland, NV, Heerenveen, The Netherlands, sampling rate $100-500 \mathrm{kHz}$, vertical resolution at least 11 bit, record length 5000-15 000 points per single sweep). Four EODs per fish and day were recorded. EOD recordings were transferred to a PC and normalized to a head-positive peak amplitude of $1 \mathrm{~V}$, using the signal analysis software package FAMOS 4.0 (IMC, Berlin, Germany, custom-made routines). The P:N ratio was calculated as the ratio of positive peak amplitude ( $\mathrm{P}$ amplitude) over the negative peak amplitude ( $\mathrm{N}$ amplitude). The duration of the positive phase ( $\mathrm{P}$ duration) and the duration of the negative phase ( $\mathrm{N}$ duration) were estimated using a threshold criterion of $\pm 5 \%$ of the positive peak amplitude for start and termination of the phases (see Fig. 1). EOD duration variables were calculated from day 34 on, when the recording chamber was placed in an aquarium for temperature stability. Four normalized EOD recordings per fish and day were averaged to reduce noise. For comparison, EODs from adult fish were recorded during the day when the fish were resting.

The very first EOD recordings were weak and thus the noise level relatively high. Also some of these very first EODs were essentially monopolar. If possible, the P:N ratio and EOD duration were estimated from displays on the PC screen, using zoom and cursor functions of the FAMOS package. These functions were also used to estimate intervals between EODs or EODs and preceding potentials.

To catch the larvae or juveniles it was usually necessary to remove the decoration material from the aquarium completely. Ten or 11 larvae were caught and kept 


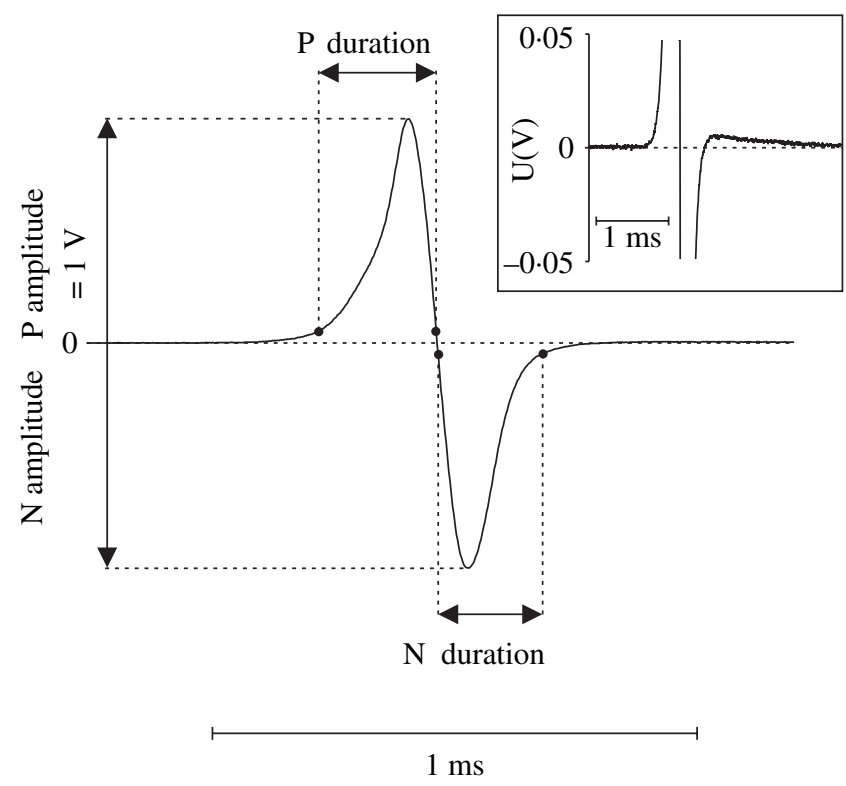

FIG. 1. Electric organ discharge (EOD) of an adult Marcusenius macrolepidotus (male; $L_{\mathrm{S}}, 18 \cdot 1 \mathrm{~cm}$; water temperature $23.9^{\circ} \mathrm{C}$ ). The inset shows the weak postpotential at stronger amplification. EOD recordings were normalized to a head-positive peak amplitude ( $\mathrm{P}$ amplitude) of $1 \mathrm{~V}$, as shown here. The duration of the first, positive phase ( $\mathrm{P}$ duration) and the duration of the second, negative phase ( $\mathrm{N}$ duration) in adult and larval EODs were estimated at $\pm 5 \%$ of the positive peak amplitude. In adult individuals the $\mathrm{P}: \mathrm{N}$ ratio ( $\mathrm{P}$ amplitude: $\mathrm{N}$ amplitude) was $c .1$.

temporarily in a 21 glass container or a 101 plastic bucket with aquarium water. This water was also used for the recording chambers. For temperature stability, the glass container or bucket floated in the aquarium where the recordings were made. Still later, the juveniles were manoeuvred into a corner of their aquarium prior to the recordings, where they were kept far away from the recording electrodes by a solid plastic partition.

In the youngest larvae, standard length $\left(L_{\mathrm{S}}\right)$ was estimated from a $0.5 \mathrm{~cm}$ scale on the pipette that was used to transfer fish into the recording cuvettes. From day 17 on, each single larva was transferred after EOD recording into a Petri dish, placed on graph paper (with $\mathrm{mm}$ subdivisions). The larva were anaesthetized lightly with MS 222. In small larvae a dissection microscope was used for estimation of $L_{\mathrm{S}}$.

\section{RESULTS}

The EOD of adult fish was bipolar. A head-positive phase was followed by a head-negative phase of similar amplitude and duration. The EOD was terminated by a very weak postpotential (Fig. 1).

Larvae hatched on day 4 or 5 and the first EODs were recorded on day 9 or 10 at an $L_{\mathrm{S}}$ of $c .6 .5 \mathrm{~mm}$ [Figs 2 and 3(a)]. The next day most EODs had stabilized to a virtually monopolar waveform, with a strong head-positive phase followed by a weak head-negative phase of long duration [Fig. 3(b)]. Compared to adult and juvenile EODs, these early EODs were of much longer duration: P duration was $c$. 1-2 ms at the onset of discharging, but decreased soon 


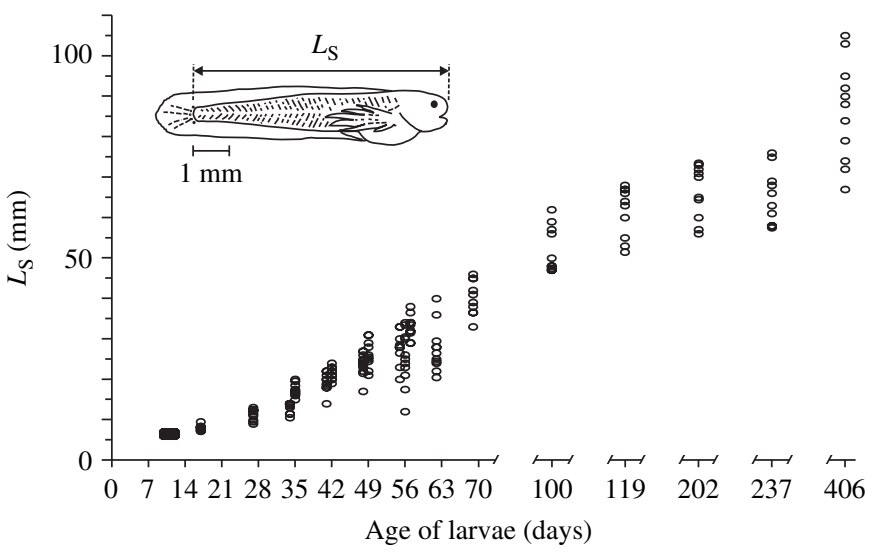

FIG. 2. Standard lengths $\left(L_{\mathrm{S}}\right)$ of Marcusenius macrolepidotus larvae that were caught for EOD recordings ( 10 or 11 larvae per session). Day $0=$ spawning. Each point is one individual on a particular day. A drawing of a larva that was found dead on day 15 is inserted.

after. Temperature could not be controlled in the recording cuvettes but room temperature was maintained at $c .21^{\circ} \mathrm{C}$. A small separate potential preceded the EOD [Fig. 3(a), (b)]. While larvae grew, the relative amplitude of this potential decreased compared to the rising EOD amplitude. At a water temperature of $24^{\circ} \mathrm{C}$ it preceded the EOD by c. $1.6 \mathrm{~ms}$ [Fig. 3(c)]. Only rarely double EODs were recorded [Fig. 3(d)], or small potentials similar to the weak preceding potential of Fig. 3(b) but following an EOD [Fig. 3(e)].

While the larvae grew (Fig. 2), the EOD waveform gradually changed into that of an adult EOD (Fig. 4). The most prominent changes observed were a decrease in the P:N ratio [Fig. 4(a)], combined with a decrease in $\mathrm{N}$ duration, whereas $\mathrm{P}$ duration decreased only slightly [Fig. 4(b)]. The strongest changes occurred at an $L_{\mathrm{S}}$ of $17-27 \mathrm{~mm}$. Here the P:N ratio changed from $c .5$ to $<1$, and the $\mathrm{N}$ duration decreased from $c .1 \mathrm{~ms}$ to $c \cdot 0 \cdot 1 \mathrm{~ms}$ (the $\mathrm{P}$ duration decreased from $c .0 .3 \mathrm{~ms}$ to $<0.2 \mathrm{~ms}$ ). At this stage a strong variability occurred within and between individuals, as in the very first EODs. From an $L_{\mathrm{S}}$ of $c .30 \mathrm{~mm}$ on the $\mathrm{P}: \mathrm{N}$ ratio as well as the $\mathrm{N}$ duration increased slightly again and there was very little variation both within and between individuals [Fig. 4(a), (b) insets].

Whereas in the larval EOD waveform, the negative phase approached the zero-line asymptotically [Figs 3 and 5(a), (b)], in the adult EOD waveform the negative phase was terminated by a weak positive postpotential [Figs 1 inset and 5(f)]. In some larvae $\left(L_{\mathrm{S}}, 25-31 \mathrm{~mm}\right)$ transitional stages were recorded, where the postpotential emerged as an inflection on the rising edge of the negative phase [Fig. 5(c)-(e)].

Although larval EOD field strength could not be measured precisely (with exactly positioned larvae relative to the electrodes), it is obvious that EOD amplitude increased strongly with $L_{\mathrm{S}}$. For example, compared to larvae of an age of 34 days $\left(L_{S}, 10 \cdot 5-14 \cdot 0 \mathrm{~mm}\right)$, larvae of an age of 69 days $\left(L_{\mathrm{S}}, 33-46\right.$ $\mathrm{mm}$ ) generated an EOD of $c$. nine-fold measured $\mathrm{P}$ amplitude, even though the distance of the recording electrodes was increased from $c .3 .5$ to $c .8 \mathrm{~cm}$. 
(a)

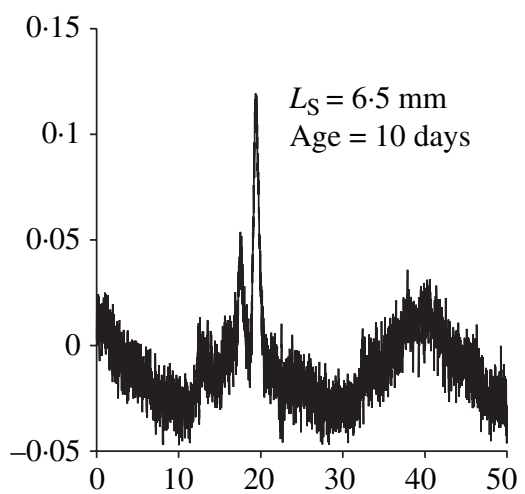

(b)

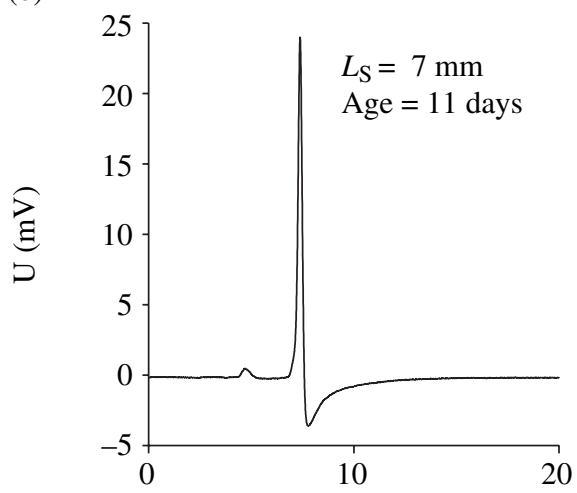

(c)

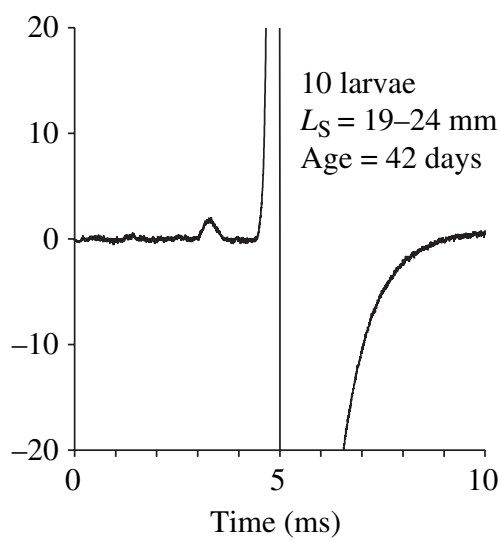

(d)

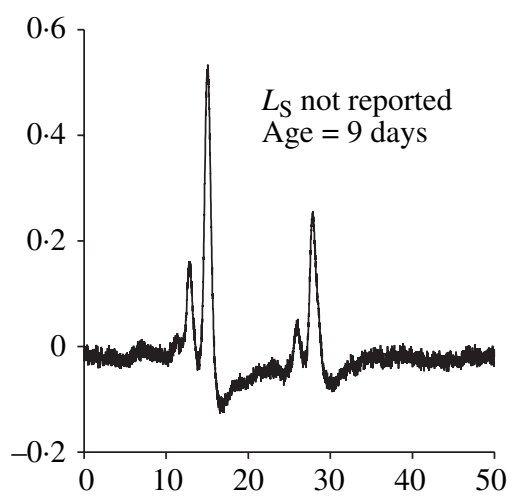

(e)

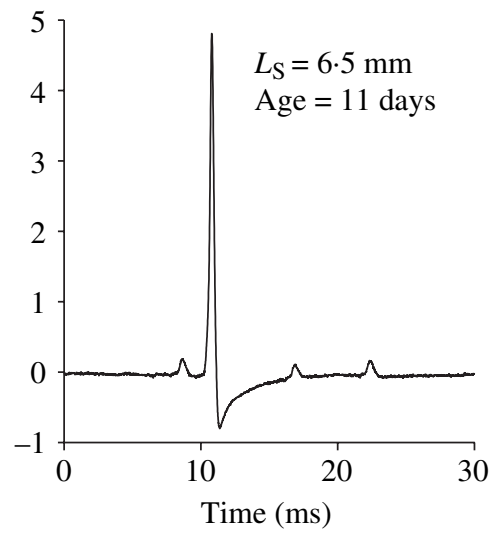

(f)

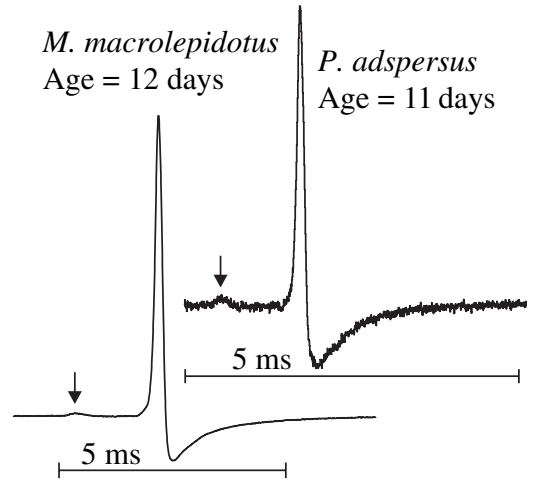

FIG. 3. (a), (b) Early EODs from Marcusenius macrolepidotus larvae, recorded head-positive in a $1 \mathrm{ml}$ recording cell. Within a few days after the onset of discharging (a) the EOD stabilized to show the typical waveform of larvae (b). (c) Normalized and averaged EOD recordings of 10 older larvae (four recordings per individual; water temperature $24^{\circ} \mathrm{C}$ ) shown at strong amplification. Note weak potential, preceding the main EOD by c. $1.6 \mathrm{~ms}$, still present. Only in a few cases double EODs (d) or multiple small potentials (e) were recorded. (f) Larval EODs from M. macrolepidotus (present study, 
At least one recording per larva and day included a period of $c .15 \mathrm{~ms}$ before and after the EOD. Except for the very first EODs, no more than a single EOD was recorded during a single-sweep trace. In particular, no pairs of EODs occurred, consisting of a larval EOD followed by an adult EOD at fixed latency of $c$. $0.7 \mathrm{~ms}$, as observed in $P$. adspersus at 40-80 days of age [Fig. 4(c), (d)].

\section{DISCUSSION}

The occurrence and development of EODs in P. adspersus larvae was studied in detail by Westby \& Kirschbaum (1977, 1978). Pollimyrus adspersus larvae started discharging on day 8 after spawning (water temperature $27^{\circ} \mathrm{C}$ ), $1-2$ days earlier than M. macrolepidotus larvae. This difference is most likely due to the lower water temperature used in the present study. Waveform, polarity and duration of the larval EOD of $M$. macrolepidotus were similar to the larval EOD in $P$. adspersus [Fig. 3(f)], and in both species of greater duration than the adult EOD. The almost monopolar larval EOD of $M$. macrolepidotus and $P$. adspersus is apparently a symplesiomorphic feature, resembling the EOD of Gymnarchus niloticus Cuvier, the only representative of the sister family, Gymnarchidae (Kirschbaum, 1995). Similar to P. adspersus, a separate small potential preceded the larval EOD in $M$. macrolepidotus. Westby \& Kirschbaum (1978) concluded that this potential (termed $p$ ), which preceded the EOD by c. $1.4 \mathrm{~ms}$ (water temperature $27^{\circ} \mathrm{C}$ ), was the summed postsynaptic potential activity in the larval electrocyte stalks, resulting from the second of the three electromotoneuron command pulses (three command pulses; Bennett, 1971). It was the strongest prepotential and remained detectable until the larval EOD began to vanish at an $L_{\mathrm{S}}$ of $c .21 \mathrm{~mm}$. The somewhat longer delay of $1.6 \mathrm{~ms}$ observed in M. macrolepidotus larvae seems to be due to the lower water temperature $\left(24^{\circ} \mathrm{C}\right)$ used in the present study.

In the first $70 \mathrm{~h}$ after EOD onset, multiple EODs occurred in $P$. adspersus larvae, with IDIs of 6-12 ms, perhaps evidence of a 'self-echoing effect' (Westby \& Kirschbaum, 1977). Only a few double EODs were recorded in M. macrolepidotus larvae, possibly because of the smaller number of recordings during the critical period, and the maximum recording length per trace of only $60 \mathrm{~ms}$.

Apart from a strong increase in amplitude, the basic waveform of the larval EOD in $P$. adspersus remained stable for the time of its existence. Up to an $L_{\mathrm{S}}$ of c. $17 \mathrm{~mm}$ (40 days) this also holds for M. macrolepidotus larvae, as indicated by the first plateau in the P:N ratio [see Fig. 4(a)]. The subsequent transition to the adult EOD, however, differed strongly between the two species: unlike in $P$. adspersus, there were no two distinct larval and adult EODs in M. macrolepidotus. Instead, the larval EOD waveform that was initially similar to that observed in $P$. adspersus larvae, was gradually transformed into the adult $M$. macrolepidotus EOD waveform.

Fig. 3. (Continued). recorded at c. $21^{\circ}$ C) and Pollimyrus adspersus (from Postner \& Kramer, 1995; recorded at c. $26^{\circ} \mathrm{C}$; note different time scale). Note the virtual identity of the EOD waveforms, including the separate small potential preceding the EOD $(\downarrow)$. 
(a)

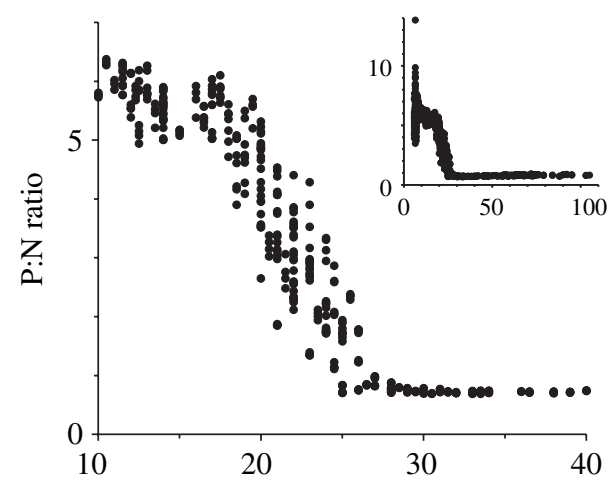

(b)

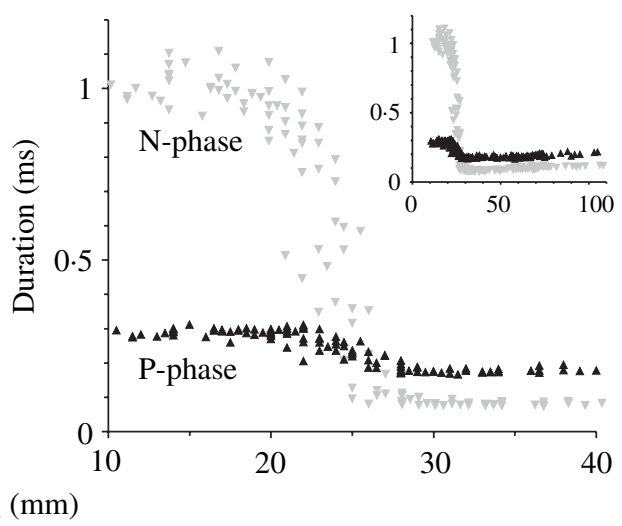

(c)

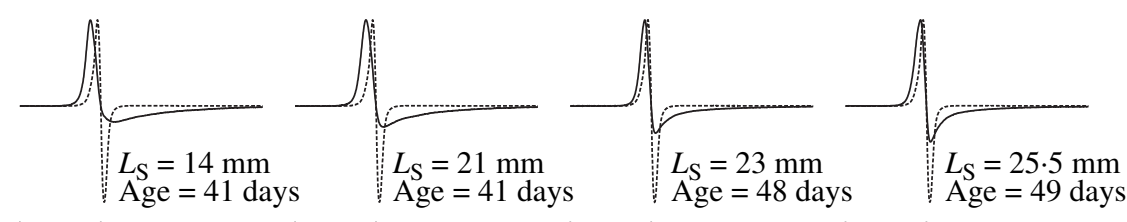

$1 \mathrm{~ms}$
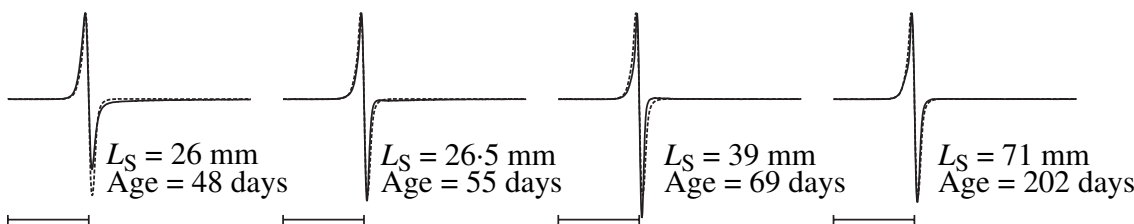

(d)

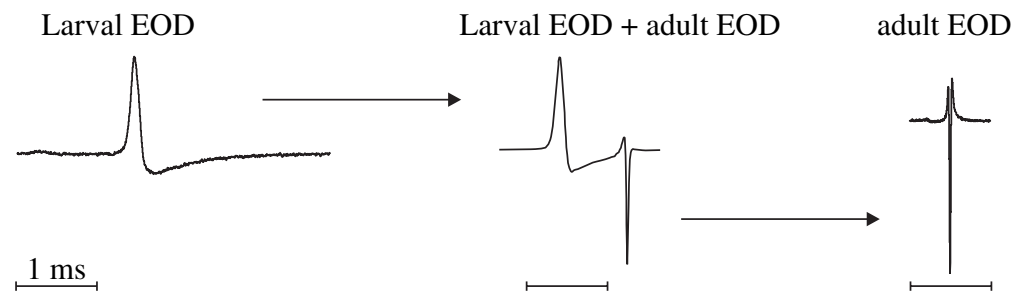

FIG. 4. (a)-(c) Development of EOD in Marcusenius macrolepidotus and (d) in Pollimyrus adspersus. (a) Development of the P:N ratio with growth. (b) Development of P duration ( $\mathbf{\Delta})$ and $\mathrm{N}$ duration $(\nabla)$ with growth (water temperature $24^{\circ} \mathrm{C}$, range $\pm 0 \cdot 2^{\circ} \mathrm{C}$ ). The insets show all data, whereas the main figures show the period of strongest change (from c. 17-27 $\mathrm{mm} L_{\mathrm{S}}$ ). (c) Examples of waveforms to illustrate the gradual transition from larval to adult EOD. — - Normalized individual larval EODs, they are superimposed on an adult EOD waveform (averaged from three females, $L_{\mathrm{S}}, 16 \cdot 0-19 \cdot 4 \mathrm{~cm}$; -----) water temperature $24^{\circ} \mathrm{C}$, range $\pm 0 \cdot 2^{\circ} \mathrm{C}$. (d) Around day 40 , in juvenile $P$. adspersus the adult EOD appears as a second discharge, following the larval EOD at fixed delay. From then on the larval EOD gets weaker and finally vanishes while the adult EOD rapidly increases in strength (from Kramer, 1996; water temperature 26-27 $\mathrm{C}$ ). Note the contrast to the gradual transformation of a single EOD in M. macrolepidotus. 
(a)

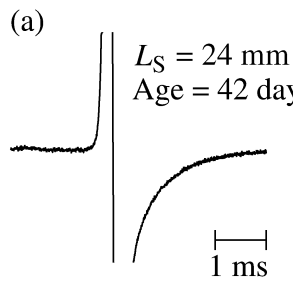

(d) (b)

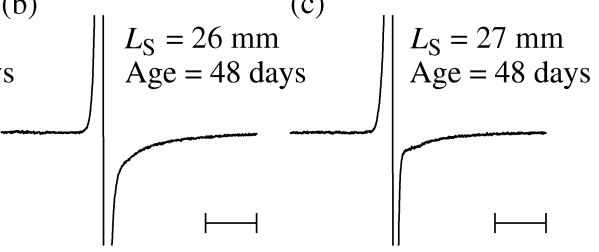

(e)

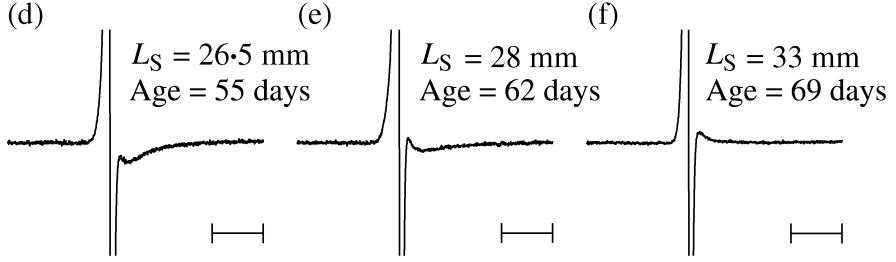

FIG. 5. (a)-(f) EOD examples (normalized individual waveforms, ordinate clipped at $\pm 100 \mathrm{mV}$ ) illustrating the emergence of the weak postpotential as present in the adult EOD in Marcusenius macrolepidotus. Note that it is already clearly visible but not yet crossing the zero-line in (d). This occurs only in (e).

The morphological background for this transformation needs to be studied. The virtual identity of the larval EOD waveform of M. macrolepidotus and $P$. adspersus [Fig. 3(f)] indicates a similarity of their larval electric organs in both morphology and physiology. Because of the gradual transformation from the larval into the adult EOD waveform, however, in M. macrolepidotus there is no evidence for two separate, serially arranged electric organs as in $P$. adspersus. Based on histological studies and larval EOD recordings, Schugardt (1997) suggested the presence of a separate larval electric organ in the body trunk and an adult electric organ in the caudal peduncle (as in P. adspersus) for Campylomormyrus cassaicus (Poll) and Mormyrus rume proboscirostris Boulenger. The larvae of these two species showed a gradual transformation from the larval into the adult EOD waveform similar to $M$. macrolepidotus of the present study. Schugardt (1997), however, did not explain why there was no temporal delay between the discharges of the two electric organs as observed in P. adspersus.

Various suggestions were made why the simple and less efficient larval electric organ was not lost during evolution in mormyrids, and functionally replaced by the highly efficient adult organ. A distinct larval EOD might serve a function in the complex parental behaviour in P. adspersus (Westby \& Kirschbaum, 1978). Parental care stops when the adult EOD waveform appears in the young fish. Two additional Pollimyrus species [Pollimyrus castelnaui (Boulenger) and Pollimyrus marianne (Kramer, van der Bank, Flint, SauerGürth \& Wink)] also showed parental care and a distinct larval and adult EOD (Lamml \& Kramer, 2005; Baier et al., 2006). Marcusenius macrolepidotus shows a larval EOD, too, but differs from $P$. adspersus by a complete lack of parental care (Werneyer \& Kramer, 2005). Because of the small number of species studied (Westby \& Kirschbaum, 1977, 1978; Schugardt, 1997; Werneyer \& Kramer, 2005; present study) it is not yet clear whether the different pathways 
of transformation from larval to adult EOD are correlated with the lack or the presence of parental care.

Regardless of possible differences in the anatomical background, the larvae of all mormyrid species that have been studied so far start generating EODs very early in life (at an age of 8-9 days). This supports the idea that the larval EOD is necessary for autostimulation of the electrosensory system during development (Postner \& Kramer, 1995; Kramer \& Postner, 1997). The complex adult organ needs more time for development and cannot perform this stimulation function right from the beginning.

In addition to their larval electric organ with its distinct larval EOD, C. cassaicus, M. r. proboscirostris and $P$. adspersus larvae also possess specific, larval electroreceptors of the tuberous kind (Denizot et al., 1998; Bensouilah et al., 2002). Studies on electrosensory thresholds in young $P$. adspersus larvae (with a larval and no adult EOD) revealed that they were most sensitive (tuned) to monopolar, single-cycle sine-wave pulses of $c .1 \mathrm{~ms}$ with waveform and spectral peak amplitude close to that of their larval EOD $(1 \mathrm{kHz})$. In older larvae, but already before the adult EOD emerged, the larval sensitivity increased and extended to higher frequencies, showing broadband tuning as observed in adult fish (Postner \& Kramer, 1995). Postner \& Kramer (1995) concluded that the electrosensory system of younger larvae was tuned to the waveform of larval EODs, whereas the following change to broadband tuning prepares the larvae for sensing any EODs, including those from their father as well as other adults, which are potential predators. This sensitivity change occurs just before the larvae develop the adult EOD when they are evicted aggressively by their father from his territory. The loss of waveform specificity, is apparently not accompanied by a loss of waveform sensitivity, since the adult fish is exquisitely waveform sensitive (Paintner \& Kramer, 2003). Nothing is known about larval electroreceptors in M. macrolepidotus and their tuning properties.

Compared to $P$. adspersus, M. macrolepidotus shows an alternative pathway of EOD ontogeny, apparently correlated with different reproductive strategies. This pathway seems to be shared by other mormyrid species, such as C. cassaicus and M. r. proboscirostris. Much remains, however, to be studied in the c. 200 mormyrid species.

We wish to thank G. Stöckl for excellent technical assistance with the electronic apparatus. Prior observations on M. macrolepidotus larvae by I. Kaunzinger (unpubl. data) were very helpful. The observations and experiments comply with the current laws of Germany. This work was supported by the Deutsche Forschungsgemeinschaft (DFG), grants Kr446/10-4, KR446/11-1, Kr446/11-2 and Kr446/11-3.

\section{References}

Baier, B., Lamml, M. \& Kramer, B. (2006). Ontogeny of the electric organ discharge in two parapatric species of the dwarf stonebasher, Pollimyrus castelnaui and P. marianne (Mormyridae, Teleostei). Acta Zoologica (Stockholm) 87, $203-214$.

Bell, C. C., Myers, J. P. \& Russell, C. J. (1974). Electric organ discharge patterns during dominance related behavioral displays in Gnathonemus petersii (Mormyridae). Journal of Comparative Physiology 92, 201-228.

Bennett, M. V. L. (1971). Electric organs. In Fish Physiology, Vol. V (Hoar, W. S. \& Randall, D. J., eds), pp. 347-491. London, New York: Academic Press. 
Bensouilah, M., Schugardt, C., Roesler, R., Kirschbaum, F. \& Denizot, J. P. (2002). Larval electroreceptors in the epidermis of mormyrid fish: I. Tuberous organs of type A and B. Journal of Comparative Neurology 447, 309-322.

Bratton, B. O. \& Kramer, B. (1989). Patterns of the electric organ discharge during courtship and spawning in the mormyrid fish, Pollimyrus isidori. Behavioral Ecology and Sociobiology 24, 349-368.

Crawford, J. D. (1997). Hearing and acoustic communication in mormyrid electric fishes. Marine and Freshwater Behavioural Physiology 29, 65-86.

Denizot, J. P., Kirschbaum, F., Westby, G. W. M. \& Tsuji, S. (1978). The larval electric organ in the weakly electric fish Pollimyrus (Marcusenius) isidori (Mormyridae, Teleostei). Journal of Neurocytology 7, 165-181.

Denizot, J. P., Kirschbaum, F., Westby, G. W. M. \& Tsuji, S. (1982). On the development of the adult electric organ in the mormyrid fish Pollimyrus isidori (with special focus on the innervation). Journal of Neurocytology 7, 165-181.

Denizot, J. P., Kirschbaum, F., Schugardt, C. \& Bensouilah, M. (1998). Larval electroreceptors indicate a larval electric system in mormyrids. Neuroscience Letters $\mathbf{2 4 1}$, $103-106$.

Heymer, A. \& Harder, W. (1975). Erstes Auftreten der elektrischen Entladungen bei einem jungen Mormyriden. Naturwissenschaften 62, 489.

Hopkins, C. D. (1999). Design features for electric communication. Journal of Experimental Biology 202, 1217-1228.

Kirschbaum, F. (1995). Reproduction and development in mormyriform and gymnotiform fishes. In Electric Fishes: History and Behavior (Moller, P., ed.), pp. 267-302. London: Chapman \& Hall.

Kirschbaum, F. \& Schugardt, C. (2002). Reproductive strategies and developmental aspects in mormyrid and gymnotiform fishes. Journal of Physiology Paris 96, 557-566.

Kramer, B. (1990). Electrocommunication in Teleost Fishes. Behavior and Experiments. Berlin: Springer.

Kramer, B. (1996). Electroreception and Communication in Fishes. Stuttgart: Gustav Fischer.

Kramer, B. \& Bauer, R. (1976). Agonistic behaviour and electric signalling in a mormyrid fish, Gnathonemus petersii. Behavioral Ecology and Sociobiology 1, 45-61.

Kramer, B. \& Kuhn, B. (1993). Electric signaling and impedance matching in a variable environment. Naturwissenschaften 80, 43-46.

Kramer, B. \& Postner, M. (1997). Development of electrical signalling in larvae of the African fish, Pollimyrus adspersus (Mormyridae, Teleostei): the patterns of interdischarge intervals. Journal of Zoology 243, 329-340.

Kramer, B. \& Westby, G. W. M. (1985). No sex difference in the waveform of the pulse type electric fish Gnarhonemus petersii (Mormyridae). Experientia 41, $1530-1531$.

Lamml, M. \& Kramer, B. (2005). Sound production in the reproductive behaviour of the weakly electric fish Pollimyrus marianne Kramer et al. 2003 (Mormyridae, Teleostei). Bioacoustics 15, 51-78.

Lissmann, H. W. (1958). On the function and evolution of electric organs in fish. Journal of Experimental Biology 35, 156-191.

Lissmann, H. W. \& Machin, K. E. (1958). The mechanism of object location in Gymnarchus niloticus and similar fish. Journal of Experimental Biology 35, 451-486.

Moller, P. (1995). Electric Fishes: History and Behavior. London: Chapman \& Hall.

Paintner, S. \& Kramer, B. (2003). Electrosensory basis for individual recognition in a weakly electric mormyrid fish, Pollimyrus adspersus (Guenther, 1866). Behavioral Ecology and Sociobiology 55, 197-208.

Postner, M. \& Kramer, B. (1995). Electrosensory thresholds in larvae of the weakly electric fish Pollimyrus isidori (Mormyridae, Teleostei) during ontogeny. Journal of Experimental Biology 198, 783-791.

Scheffel, A. \& Kramer, B. (1997). Electrocommunication and social behaviour in Marcusenius senegalensis (Mormyridae, Teleostei). Ethology 103, 404-420. 
Scheffel, A. \& Kramer, B. (2000). Electric signals in the social behavior of sympatric elephantfish (Mormyridae, Teleostei) from the Upper Zambezi River. Naturwissenschaften 87, 142-147.

Scheffel, A. \& Kramer, B. (2006). Intra- and interspecific electrocommunication among sympatric mormyrids in the Upper Zambezi River. In Communication in Fishes (Ladich, F., Collins, S. P., Moller, P. \& Kapoor, B. G., eds), pp. 733-751. Enfield, NH: Science Publishers.

Schugardt, C. (1997). Experimentelle Untersuchungen zur exogenen Kontrolle der zyklischen Fortpflanzung afrikanischer Süßwasserfische: Vergleich von Mormyriden und Polypterus. Doctoral Dissertation, Humboldt-Universität of Berlin.

Szabo, T. (1960). Development of the electric organ of the mormyridae. Nature (London) 188, 760-762.

Werneyer, M. \& Kramer, B. (2002). Intraspecific agonistic interactions in freely swimming mormyrid fish, Marcusenius macrolepidotus (South African form). Journal of Ethology 20, 107-121. doi: 10.1007/s10164-002-0062-y

Werneyer, M. \& Kramer, B. (2005). Electric signalling and reproductive behaviour in a mormyrid fish, the bulldog Marcusenius macrolepidotus (South African form). Journal of Ethology 23, 113-125. doi: 10.1007/s10164-004-0136-0

Westby, G. W. M. \& Kirschbaum, F. (1977). Emergence and development of the electric organ discharge in the mormyrid fish, Pollimyrus isidori. I. The larval discharge. Journal of Comparative Physiology 122, 251-271.

Westby, G. W. M. \& Kirschbaum, F. (1978). Emergence and development of the electric organ discharge in the mormyrid fish, Pollimyrus isidori. II. Replacement of the larval by the adult discharge. Journal of Comparative Physiology 127, 45-59. 